\title{
Stability Constraints of the Transmission Capacity about VSC-HVDC System Supply to the Passive Network
}

\author{
S. Chen, X. Tang, W.Q. Zhang \\ College of Electrical and Informaton Engineering \\ Changsha University of Science and Technology \\ Changsha 410000, Hunan Province, China
}

\begin{abstract}
- the external volt-ampere characteristic of the rectifier and inverter station of the VSC-HVDC (Voltage Sourced Converter-High Voltage Direct Current) system is simplified and the dc network equivalent circuit of VSC-HVDC system is built. The small signal model of the VSC-HVDC system is then derived. The transmission capacity is calculated under small-signal stability constraints and three influence factors are also obtained. Simulation is conducted by using PSCAD/EMTDC software. The simulation results demonstrate that the transmission capacity of VSCHVDC system supply a passive network is be quite affected by the DC voltage, DC-side capacitance, and the resistance and reactance of the DC transmission lines.
\end{abstract}

Keywords-VSC-HVDC; equivalent circuit; small signal stability; transmission capacity

\section{INTRODUCTION}

With the electric field and areas expanding, the scale of the grid is expanding rapidly. HVDC is characterized by a number of technical merits: relatively lower cost in the long-distance and large-capacity power transmission, without the phenomena of system operational stability constraint, and smaller charging capacitance of DC cable. With these advantages, the HVDC has a broad application in asynchronous ac-grid interconnection, long-distance and large-capacity power transmission, and power transmission with cables, etc [1]-[3]. The recently developed HVDC technology based on voltage-sourced converters (VSC), namely VSC-HVDC, have some clear advantages. It can control the active and reactive power independently, and there is no need for the commutation-capacity. Based on these, the new developed technology is being applied in the connection of wind power [4]-[6], and feeding of weak grid [7]-[8] and the passive loads [9]-[12].

The main factors that affecting the maximum transmission power on long-distance AC transmission can be known as follows: thermal limits, constraints of voltage loss and the stability constraints of maintaining the synchronous running on the both ends of connected AC system.

The grid frequency of two regional can be decoupled through HVDC interconnection. It is no longer restricted by the stability constraints of synchronous operation. However, large enough commutation-capacity need to be provided by receiving grid in the traditional high voltage dc transmission system, so the strength of receiving grid (or the size of the short-circuit ratio) is an important impacting factor on the power/voltage stability [13]-[16].

For the VSC-HVDC is concerned, commutation-capacity is no longer needed. That is to say, the strength of receiving grid has a little effect on maximum transmission capacity. In order to ensure the power quality, VSC-HVDC system supplying to passive network can control the voltage of inverter connect to $\mathrm{AC}$ bus with fast and indifference. The responding speed of $\mathrm{AC}$ bus voltage to the disturbances of DC side is under milliseconds [17]. So the load of the DC system (as viewed from the DC side of the inverter station) presents constant power characteristics, which weakened DC voltage stability of the network, thereby restricting the maximum transmission power of the VSC-HVDC system feeding of the passive network.

Due to the responding speed of the supply-side disturbances controlled by inverter station of VSC-HVDC systems supplying to passive network bellows milliseconds and line electromagnetic transient response belong to the same time scale. Therefore, in this paper, through the establishment of the VSC-HVDC system dynamic model that consider the line of electromagnetic transient and feeding of passive network, the voltage stability of DC network is analyzed. And then the quantitative calculation formula for the transmission capacity of the VSC-HVDC systems is deduced.

\section{MODEL OF SYSTEM}

\section{A. Description of the System}

Fig. 1 shows the structure of the VSC-HVDC system supply to the passive network. As shown, converter station is the voltage-source cnverter with sinusoidal pulse width modulation; the inverter station and the rectifier station are connected by dc transmission lines, while rectifier station connects with the large power grid. The series combination of $\mathrm{AC}$ side inductance $\mathrm{L}$ and resistance $\mathrm{R}$ indicate converter transformer and converter reactors between the PCC (Point of Common Coupling) and converter station; The series combination of inductance LS and resistance RS represents the equivalent impedance of the AC system; AC filter and converter reactors are used to filter out the high-frequency components generated by the switching converter station; DC capacitor is used to reduce the DC voltage fluctuation; Where Req and Leq are equivalent resistance and reactance of the DC transmission line, Ceq represents equivalent capacitance in parallel by the distributed capacitance and DC capacitor. 


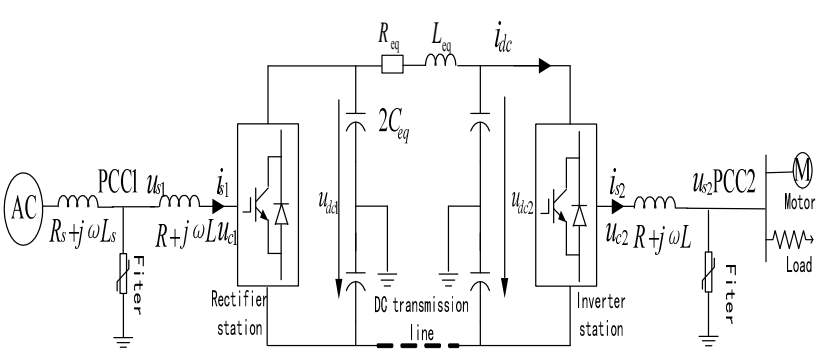

FIGURE I. THE STRUCTURE OF THE VSC-HVDC SYSTEM.

\section{B. The Constant Power Load Characteristics of DC Network}

When the VSC-HVDC system supply power to the passive network, its inverter station usually adopted AC voltage and fixed frequency control strategy, in order to ensure power quality, the response time of disturbance affected by voltage control is under milliseconds, therefore, DC network presents a constant power load characteristics (the view of the inverter station from the DC side). Fig. 2 shows the constant power load characteristic curve. The volt-ampere characteristics are obtained in (1).

$$
i=\frac{P_{C P L}}{v}
$$

Where $\mathrm{i}$ is the current flowing into the load, $\mathrm{v}$ is the voltage at the end of the load, $\mathrm{P}_{\mathrm{CPL}}$ is the load power. Formula $\left(\mathrm{I}=\mathrm{P}_{\mathrm{CPL}} / \mathrm{V}\right)$ can be turned into a linear in the equilibrium point, as given by (2).

$$
i=2 \frac{P_{C P L}}{V}-\frac{P_{C P L}}{V^{2}} V
$$

As can be seen from the above equation, the impedance characteristics of the constant power load are nonlinear, and the input impedance of small-signal is negative.



FIGURE II. THE VOLT AMPERE CHARACTERISTICS OF THE CONSTANT POWER LOAD.

\section{Simplified Model of VSC-HVDC System}

In this paper, rectifier station of the VSC-HVDC system supply power to passive network using fixed-voltage control, to maintain the level of DC voltage and active power balance of the entire network, its external characteristics performs a constant voltage source, thereby, as shown in fig.3, the simplifying circuit system can be obtained, and thus the equilibriuem quations of the system is given by (3) and (4).

$$
\begin{gathered}
\frac{d i_{l}}{d t}=\frac{1}{L}\left(v_{c 1}-v_{c 2}\right)-i_{l} R_{e q}=\frac{1}{L}\left(v_{c 1}-v_{c 2}\right)-i_{l} R_{e q} \\
\frac{d v_{c 2}}{d t}=\frac{1}{c}\left(i_{l}-i_{C P L}\right)=\frac{1}{c}\left(i_{l}-f\left(v_{c 2}\right)\right)
\end{gathered}
$$

Where $\mathrm{f}\left(\mathrm{v}_{\mathrm{c} 2}\right)$ is the volt-ampere characteristics of constant power load.

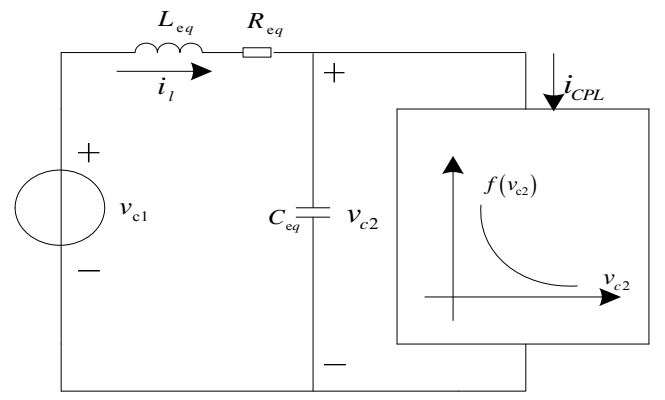

FIGURE III. SIMPLIFIED CIRCUIT DIAGRAM OF THE SYSTEM.

\section{Small Signal-StabiLity Analysis of Systems}

Due to the volt-ampere characteristics of constant power load is nonlinear, In the point of the power balance $\left(\mathrm{IL}=\mathrm{P}_{\mathrm{CPL}} / \mathrm{V}_{\mathrm{C} 2}\right)$, according to equation (2) to linearize the voltampere characteristics, (5) is obtained.

$$
f\left(v_{c 2}\right) \approx f\left(V_{c 2}\right)+\frac{1}{r_{L}} \Delta v_{c 2}
$$

In the formula, $r_{L}=-V_{c 2}^{2} / P_{C P L}$.

Appling small perturbations with $i_{l}=I_{L}+\Delta i_{l}$ and $v_{c 2}=V_{C 2}+\Delta v_{c 2} . \Delta i_{l}$ and $\Delta v_{c}$ were small interfering increments of currents and voltages. According to fomula (5), after the load was linearized, substituting the preturbed states into the fomula (3) and (4), then (6) is obtained.

$$
\left\{\begin{array}{l}
\frac{d \Delta i_{l}}{d t}=-\frac{R_{e q}}{L_{e q}} \Delta i_{l}-\frac{1}{L_{e q}} \Delta v_{c 2} \\
\frac{d \Delta v_{c 2}}{d t}=\frac{1}{\mathrm{C}} \Delta i_{l}-f\left(v_{c 2}\right) \Delta v_{c 2}
\end{array}\right.
$$

$$
\lambda^{2}+\left(\frac{R_{e q}}{L_{e q}}+\frac{1}{C_{e q} r_{L}}\right) \lambda+\frac{R_{e q}}{L_{e q} C_{e q}} \frac{1}{r_{L}}+\frac{1}{L_{e q} C_{e q}}=0
$$
as

The eigenvalues formula of the system are then expressed

$$
\lambda^{2}+\left(\frac{R_{e q}}{L_{e q}}+\frac{1}{C_{e q} r_{L}}\right) \lambda+\frac{R_{e q}}{L_{e q} C_{e q}} \frac{1}{r_{L}}+\frac{1}{L_{e q} C_{e q}}=0
$$


For pure resistive load, $r_{L}>0$, the eigenvalues of the system is in the left half plane, and when the load is constant power, $\mathrm{r}_{\mathrm{L}}<0$, the eigenvalues of the system is turned into the right half plane, the small signal stability conditions of the constant power load system can be calculated as follows:

$$
\left\{\begin{array}{l}
\frac{R_{e q}}{L_{e q}}+\frac{1}{C_{e q} r_{L}}>0 \\
\frac{R_{e q}}{L_{e q} C_{e q}} \frac{1}{r_{L}}+\frac{1}{C_{e q} L_{e q}}>0
\end{array}\right.
$$

Corresponding to the above analysis, the stability sonstraints of the transmission power can be obtained, as given by (10) and (11).

$$
\begin{gathered}
P_{C P L}<\frac{V_{C}{ }^{2} R_{e q} C_{e q}}{L_{e q}} \\
P_{C P L}<\frac{V_{C 2}^{2}}{R_{e q}}
\end{gathered}
$$

Because Req is small, the condition of formula (11) is easily meet. According to equation (10), there are three main factors that limit the maximum transmission power of the system, there are voltage level, the type of line and the value of DC side capacitance, the higher the voltage level, the greater the value of the DC side capacitor, the larger the transmission powe, the transmission power ability of submarine cable is larger than overhead transmission. Fig. 4 shows the relationship between maximum transmission power and the value of dc voltage and the capacitor of DC side. In order to further study the transmission limit power affected by the transmission distance, ignore the loss of the line, (12) is obtained.

$$
V_{C 2} \approx V_{C 1}-D r_{0} \frac{P_{C P L}}{V_{C 1}}
$$

Where $\mathrm{D}$ is the distance of transmission, $\mathrm{r} 0$ is the equivalent resistance of line per kilometer length. Using (12) in (10) and solving the resultant, (13) is obtained.

$$
P_{C P L}<\frac{1}{2} \frac{V_{C 1}^{2}}{r_{0}^{3} D^{2}} \frac{l_{0}}{C_{e q}}\left(\frac{2 D r_{0}^{2} C_{e q}}{l_{0}}+1\right)-\frac{V_{C 1}^{2}}{D r_{0}} \sqrt{\frac{1}{4} \frac{\left(2 D r_{0}^{2} C_{e q}+l_{0}\right)^{2}}{r_{0}^{4} C_{e q}^{2} D^{2}}-1}
$$

Where $1_{0}$ is the equivalent inductance of line per kilometer length.Fig. 5 shows the relationship between the transmission distance and the maximum transmission power and the linetype.

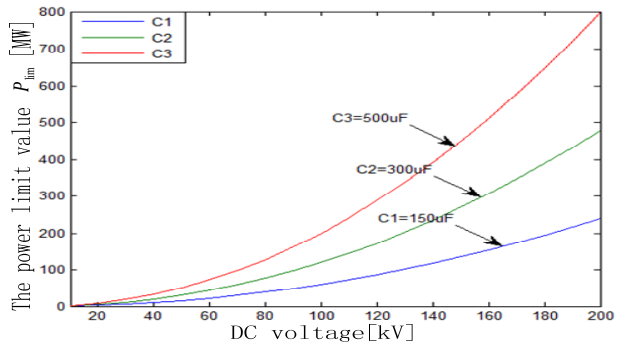

FIGURE IV. POWER LIMIT VALUES UNDER DIFFERENT DC VOLTAGE.

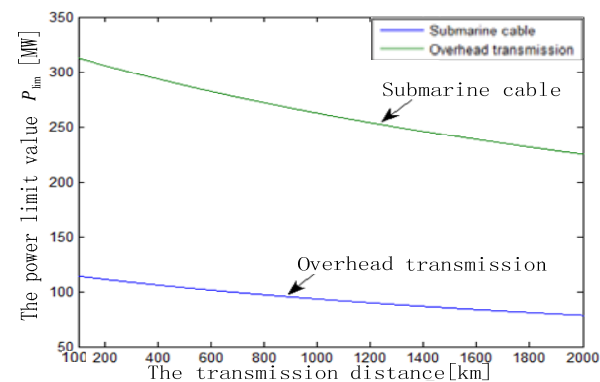

FIGURE V. POWER LIMIT VALUES UNDER DIFFERENT TRANSMISSION DISTANCE.

\section{SIMULATION}

In order to verify the correctness and validity of the analytical model proposed in this paper, the simulation model of the passive network powered by VSC-HVDC system in PSCAD/EMTDC is established, Fig. 1 showns the structure of simulation model. Table 1 showns the AC grid parameters connected with VSC-HVDC system.

TABLE I. THE PARAMETERS OF AC GRID.

\begin{tabular}{|l|l|l|}
\hline Us & AC rated voltage of rectifier & $110 \mathrm{KV}$ \\
\hline $\mathrm{L}$ & The inductance of the Commutation reactance & $0.0006 \mathrm{H}$ \\
\hline $\mathrm{R}$ & The resistance of the commutation reactance & $0.005 \Omega$ \\
\hline $\mathrm{f}$ & The frequency of the system & $50 \mathrm{~Hz}$ \\
\hline
\end{tabular}

\section{A. Instability Phenomenon}

The parameters of DC side in the simulation system are given by the following: $\mathrm{V}_{\mathrm{Cl}}=118 \mathrm{kV}, \mathrm{C}_{\mathrm{eq}}=500 \mu \mathrm{F}, \mathrm{L}_{\mathrm{eq}}=0.18 \mathrm{H}$, $\mathrm{R}_{\mathrm{eq}}=3.14 \Omega$. The ultimate power of VSC-HVDC system, $\mathrm{P}_{\mathrm{lim}}=121 \mathrm{MW}$ can be obtained by formula. Fig.6 shows the power of system increased to $121 \mathrm{MW}$ and $135 \mathrm{MW}$ respectively when strating $100 \mathrm{MW}$ in five seconds, it can be seen from the figure the system remains stable when the power increased to $121 \mathrm{MW}$, but the power appeared concussion when the power of the system has increased to $135 \mathrm{MW}$. Because of the rectifier and inverter station adopted simplified model, $121 \mathrm{MW}$ from the calculation of maximum transmitted power value is smaller than $135 \mathrm{MW}$ from the simulation to get the maximum transmission power value. 


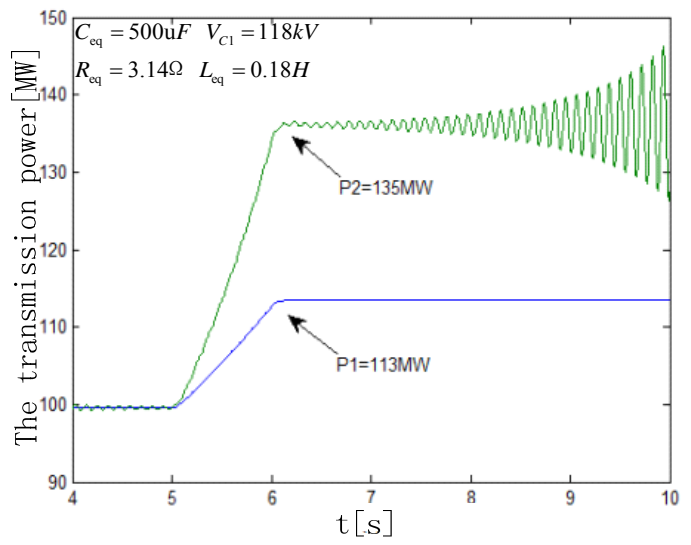

FIGURE VI. THE TRANSMISSION POWER OF THE SYSTEM.

\section{B. The Impact of Maximum Transmission Power on DC Capacitorer}

To substitute the parameters of the DC side capacitance $\left(\mathrm{C}_{\mathrm{eq}}=600 \mu \mathrm{F}\right)$ into the simulaton 3.1. According to the formula (9), the maximum transmit power of the system is $145 \mathrm{MW}$. Fig. 6 shows the power of system increased to $135 \mathrm{MW}$ and $155 \mathrm{MW}$ respectively when strating $100 \mathrm{MW}$ in five seconds, as can be seen from the Figure 7, with value of the DC side capacitor increasing, the value of the system transmission system power increased to $155 \mathrm{MW}$. The system appears a power oscillations, that is mean increase the value of DC side capacitor can increase the maximum transmission power of the system.

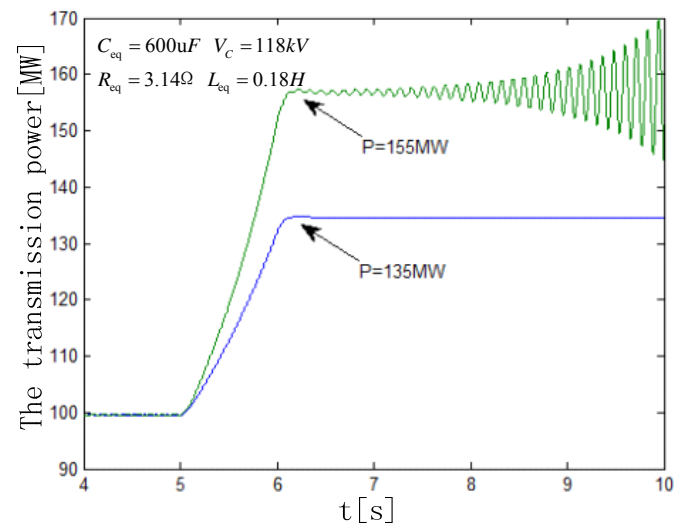

FIGURE VII. THE TRANSMISSION POWER OF THE SYSTEM WHEN DIRECT CURRENT CAPACITY IS 600MF.

\section{The Impact of Maximum Transmission Power on DC Voltage}

To substitute the parameters of the dc votltage $\left(\mathrm{V}_{\mathrm{Cl}}=130 \mathrm{kV}\right)$ into the simulaton 3.1. According to the formula (9), the maximum transmit power of the system is 147MW. Fig. 8 shows the power of system increased to $135 \mathrm{MW}$ and $158 \mathrm{MW}$ respectively when strating $100 \mathrm{MW}$ in five seconds, as can be seen from the figure, with value of the DC voltage increasing, the value of the system transmission system power increased to $158 \mathrm{MW}$. The system appears a power oscillations, that is mean increase the value of DC voltage can increase the maximum transmission power of the system.

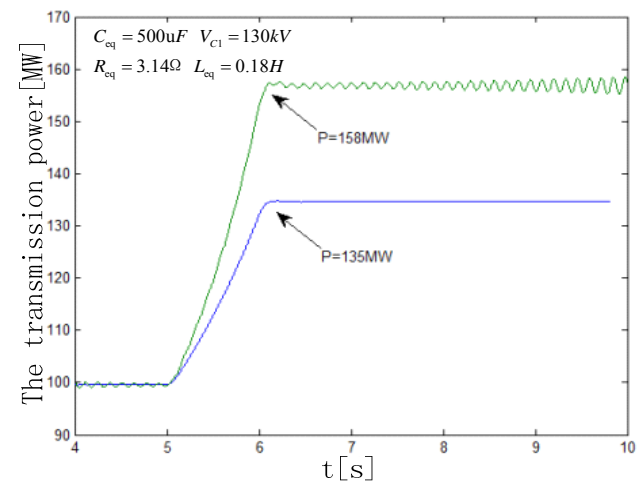

FIGURE VIII. THE TRANSMISSION POWER OF THE SYSTEM WHEN DC-SIDE VOLTAGE IS 130KV.

D. The Impact of Maximum Transmission Power on the Type of DC Line

To substitute the cable parameters of the overhead transmission into the simulaton 3.1 (the equivalent parameter of cable: reference value $\mathrm{R} 0=5 \mathrm{~m} \quad \Omega \quad \mathrm{kM}$, $\mathrm{L} 0=0.1085 \mathrm{mH} / \mathrm{kM}$ [18-19]). According to the formula (12), the transmission capacity of the system is $310 \mathrm{MW}$. Fig.9 shows the curve when transmission power of the system reach $135 \mathrm{MW}$ with two kinds of line parameters, the use of overhead line transmission make the system appear a power oscillation, and the use of cable can operation stability. That is to say that the ratio of line parameters R0 and L0 affect the maximum transmission power of the system.



FIGURE IX. THE TRANSMISSION POWER OF THE SYSTEM UNDER DIFFERENT TRANSMISSION LINES.

The formula (12) shows that the length of the HVDC transmission line will also affect the maximum transmission power of the system. Fig. 10 shows the waveform of transmission power, when the transmission power of the overhead transmission line reached $135 \mathrm{MW}$ at $100 \mathrm{kM}$ and $200 \mathrm{kM}$.Graphic shows the longer the transmission line, the lower the transport capacity of system. 


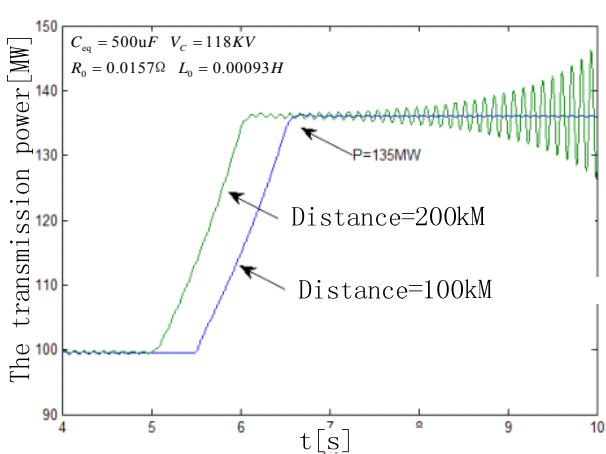

FIGURE X. THE TRANSMISSION POWER OF THE SYSTEM UNDER DIFFERENT TRANSMISSION DISTANCE.

\section{CONCLUSION}

In this paper, a small-signal stability of the VSC-HVDC system was analysed. The important affecting factors on transmission capacity of passive network powered by VSCHVDC, such as the parameters of DC voltage, DC capacitor and transmission distance, are quantitatively analyzed and simulated. From the simulation results, the following conclusion can be drawn.

1. The higher the DC voltage and DC capacitor, the greater transmission capacity of system;

2. The farther the transmission distance, the smaller transmission capacity, the capacity by the cable is larger than the overhead line transmission;

3. The Control parameters of rectifier and inverter stations have a certain influence on the transmission capacity of the system, the rectifier take a DC voltage source description, the maximum transmission capacity calculation tend to be conservative.

\section{REFERENCES}

[1] Li Xingyuan,Zhao Rui,Liu Tianqi,Wang Yuhong,Wang Xi.Research of Conventional High Voltage Direct Current Transmission System Stability Analysis and Control[J].Transactions of China Electro Technical Society,2013,10:288-300.

[2] TANG Guang fu,HE Zhi yuan,PANG Hui. Research, Application and Development of VSC-HVDC Engineering Technology[J]. Automation of Electric Power Systems ,2013,15:3-14.

[3] Long Willis,Nilsson Stig.HVDC transmission:yesterday and today[J].IEEE Power and Energy Magazine,2007,5(2):22-31.

[4] ZHAO Jing1,ZHAO Chengyong1,SUN Yiying1,ZHANG Jianpo1,JING Huabing.Low Voltage Ride-Through Technology for Wind FarmsConnected to Power Grid via MMC-Based HVDC Transmission[J]. Power System Technology. 2013,03:726-732.

[5] Bresesti P,Kling W L,Hendriks R L,et al.HVDC connection of offshore wind farms to the transmission system[J].Energy Conversion,IEEE Transactions on, 2007,22(1):37-43.

[6] Wei Xiaoguang,Tang Guangfu.Effect of VSC-HVDC applied on improving wind farm voltage stability[J].Power System Technology,2007,31(8):27-31(in Chinese)

[7] Xu Zheng.Characteristics of HVD Connected To Weak AC Systems Part1,HVDC Transmission Capability[J].Power System Technology, 1997, 01:12-16.

[8] Beccuti G, Papafotiou G,Harnefors L. Multivariable Optimal Control of HVDC Transmission Links With Network Parameter Estimation for Weak Grids[J].
[9] GUO Xiaojiang1, GUO Qiang2, MA Shiying2,XU Zhengxiong2,ZHANG Yantao2,BU Guangquan2,WANG Chengshan1. Research on System Interconnection Requirements of DC Island Sending Systems[J], Proceedings of the CSEE, 2012, 34:42-49+8.

[10] Zhang L, Harnefors L,Nee H P.Modelling and control of VSC-HVDC connected to island systems[C].Power and Energy Society General Meeting,2010 IEEE. 2010:1-8.

[11] CHEN Hai-rong, XUZheng.Control Design for VSC- HVDC Supplying Passive Ntwork[J]. proceedings of the CSEE,2006,23:42-48.

[12] LIANG Hai-feng,LI Geng-yin,LI Guang-kai,ZHANG Kai,ZHOU Ming.Simulation Study of VSC-HVDC Sytem Connected to Passive Network[J].Power System Technology,2005,08:45-50.

[13] ZHANG Yingmin1,HE Yang2,LI Xingyuan1, ZHAO Rui1,WANG Pengfeil,CHEN Hul.Analysis on Power Stability of Multi-Infeed HVDC Power Transmission System $[\mathrm{J}]$.Power System Technology,2011,35(6):50-54.(in Chinese).

[14] Yu J,Karady G G,Gu L.Applications of embedded HVDC in power system transmission[C]//Power Engineering and Automation Conference (PEAM), 2012 IEEE.IEE.2012:1-6.

[15] CHEN Hu1,ZHANG Yingmin1,HE Yang2,LI Xingyuan1,ZHAO Rui1, WANG Pengfeil. Analysis on Power Stability of Multi-Infeed HVDC Power Transmission System[J].Power System Technology,2011,06:5054.

[16] LIN Wei-fang, TANG Yong, BU Guang- quan. Definition and Application of Short Circuit Ratio for Multi-infeed AC/DC Power Systems [J]. Proceedings of the CSEE, 2008,3:1-8.

[17] Tang Xin,Li Jianlin,Teng Benke.Enhancement of Voltage Quality in a Passive Network Supplied by a VSC-HVDC System Under Disturbances [J].Transactions of China Electro Technical Society,2013,09:112-119.

[18] Li SHaskew T A,Xu L.Control of HVDC light system using conventional and direct current vector control approaches[J].Power Electronics,IEEE Transactions on,2010,25(12):3106-3118.

[19] UNITECH Power Systems,Shell."Long distance electrical power supply for subsea installation" accessed in the Internet on January 2008. 